\title{
Involvement of Male Youth into Accidents in Upper Egypt: Pattern and Risk Analysis
}

\author{
Raouf M. Afifi'1*, Sameh Sh. Zaytou'2, Ahmed A. El Raggal'3, Amani Qulali'1, \\ Hesham A. K. Ayoub ${ }^{4}$ \\ ${ }^{1}$ Community Health Institute, International Management-Health Services Inc., Indianapolis, Indiana, USA \\ ${ }^{2}$ Department of Community Medicine and Internal Medicine, South Valley University, Quena, Egypt \\ ${ }^{3}$ Health Department, Egyptian Atomic Energy Authority, Ministry of Electricity \& Energy, Cairo, Egypt \\ ${ }^{4}$ Department of Internal Medicine, Military Medical Academy, Cairo, Egypt \\ Email: ${ }^{*}$ raoufafifi@hotmail.com
}

Received 18 June 2015; accepted 10 August 2015; published 13 August 2015

Copyright (C) 2015 by authors and Scientific Research Publishing Inc.

This work is licensed under the Creative Commons Attribution International License (CC BY). http://creativecommons.org/licenses/by/4.0/

(c) (7) Open Access

\section{Abstract}

Background: Accidents pose a serious threat to health and economy in Egypt. Objectives: To identify and analyze the epidemiological factors associated with different types of accidents among adult males in Upper Egypt. Methods: A sample of 500 Egyptian males 20 - 28 years of age attending for health care at Quena University Hospital (QUH) or affiliated health institutions in South Egyptian governorates of Luxor and Red Sea was studied. The demographic, socioeconomic, and habitual data, as well as health status, medical history, and history of engagement into accidents for the recruits all were evaluated. Results: Accidents occurrences accounted up to 23/500 (4.6\%) of the studied group. Road traffic accidents (RTAs) represented the highest percentage (30.4\%), followed by street fights $(21.7 \%)$ and animal bites (13.1\%). Occupational accidents, electrical injuries, and near-drowning, all were equally encountered $(8.7 \%)$, whereas falls and burns were least prevalent ( $4.3 \%$ each). Drug abuse, manual work, obesity, and having epilepsy were significant risk factors for accident injuries $(\mathrm{OR}=6.35,95 \% \mathrm{CI}$ : $1.64-24.58, \mathrm{OR}=3.36,95 \% \mathrm{CI}$ : 1.22 9.73, $\mathrm{OR}=4.81,95 \% \mathrm{CI}: 1.50-15.46, \mathrm{OR}=45.33,95 \% \mathrm{CI}: 3.94-518.01$, respectively). Conclusions: Engagement of young Upper Egyptian males into accidents is alarming. Most of the accident mechanisms encountered are preventable. Enforcement of standard occupational, traffic and public safety laws is needed to minimize the burden of accidents upon the public health and economy in Upper Egypt.

\section{Keywords}

Accidents, Epidemiology, Males, Upper Egypt

\footnotetext{
*Corresponding author.
}

How to cite this paper: Afifi, R.M., Zaytou, S.Sh., El Raggal, A.A., Qulali, A. and Ayoub, H.A.K. (2015) Involvement of Male Youth into Accidents in Upper Egypt: Pattern and Risk Analysis. Health, 7, 965-975. 


\section{Introduction}

Safety at all settings has always been a major concern of mankind. Accidents may simply be perceived as an antonym of safety. It is often seen as threat to people's safety and security, for the damage and loss in properties, resources, and health brought about by accidents or unfavorable events is often overwhelming. Generally, the accident scene includes, but not limited to, material agents, risk elements, hazards, site environment, contact, impact, timing, span, synergetic/hampering circumstances, or any combinations of these circumstances. For, the presence of the possibility of a person either to be or not to be part of the material component of the accident, the term accident applies whether or not human bodily injury or personal harm occurs. Further, a causal link between accident and the harm is another issue to tackle. Speaking of accidents, many terminologies arise. The terms: accident, event, incident, and near-miss are often inappropriately used interchangeably, especially when no sharp demarcation between these terminologies is thought to be necessary, such as in scientific research or litigation. As such, prevention of accidents, whether at work or in other environments and whether the person is stationary or otherwise focuses on the cause of the accident [1]. (Accident causation models; thereby provide a theoretical basis for explaining how accidents occur). Further, accident definition in the context of prevention addresses the occurrence in light of accident investigation and analysis. The main purpose is to gain insight in the underlying causes in order to prevent similar future occurrences, and to improve the safety of at-risk populations. Setting clear definitions for accidents, incidents, and near-miss to reflect such purpose and to refer on how accidents occur is critical. In literature, the definition of accidents provided by Heinrich [2] as "an unplanned and uncontrolled event in which the action or reaction of an object, substance, person or radiation results in personal injury or the probability thereof" is often cited. Bird and Germain [3] define an accident as an "unintended or unplanned happening that may or may not result in property damage, personal injury, work process stoppage or interference, or any combination of these conditions under such circumstances that personal injury might have resulted." Despite the incorporation of the notion "unplanned" in this definition, more recently when the causes are determined, it is usually found that many events were predictable and could have been prevented if the right actions were taken. This implies that the occurrence is not one of fate or chance. Although the term incident is regarded more and more as a broad term encompassing all events causing injury or material damages and also near-miss events, this is not always the case. Incident is often also referred to, as "an event that has the potential to cause harm, but did not.” Incident is then regarded as a synonym for a near-miss event [4].

From the public health standpoint, accidents represent a major epidemic of non-communicable diseases at the present time; being part of the price we pay for the technological progress [5]. In developing countries, injuries are a neglected epidemic, causing more than five million deaths each year, roughly equal to the number of deaths from HIV/AIDS, malaria and tuberculosis combined. More than $90 \%$ of injury deaths occur in low- and middle-income countries, where preventive efforts are often nonexistent, and health-care systems are least prepared to meet the challenge. Of all categories of injury, RTAs have appropriately received the greatest attention. As such, injuries clearly contribute to the vicious cycle of poverty and the economic and social costs have an impact on individuals, communities and societies. Accidents are undoubtedly among the most important health problems in adolescents and young adults. They are the main leading cause of fatality and disability in this age group. Nearly three-fourths of deaths among American adolescents and young adults result from accidents either intentional or unintentional injuries [6]. Particularly those 12 - 24 years of age are at higher risk of accidents than others. Further, males are at double risk than females. Other determinants for encountering physical injuries in human are related to behavioral and habitual tendencies, as well as the health status, physical and mental capabilities; whether or not there are underlying morbidities of the challenged individuals. Drug dependents and alcoholics, for instance, are commonly incriminated in many types of accidents. Chronic medical conditions such as poor vision and epilepsy increase the risk of accidents [7]. Accidents can also be classified according to the place of occurrence [8], as 1) road traffic accidents 2) occupational accidents, 3) domestic accidents, 4) railway accidents, 5) public-places accidents, 6) recreational places accidents, and 7) other (e.g., flight accidents). In fact, RTAs are the most important and commonest type of accidents all over the world, accounting for $28 \%$ of all types of accident injuries. Annually, more than 300,000 deaths occur as a result of traffic accidents, worldwide. In addition, for every single RTA-related death there are as many as 30 - 40 minor injuries and 10 - 15 serious injuries requiring long period of expensive care and treatment [9]. Demographically, adolescents and young adults are more vulnerable to RTAs, especially males, perhaps because they are more likely to speed up, run red lights, make illegal turns or drive while intoxicated or drunk. Internationally, RTAs statistics for the 
youth are alarming, that they are the main cause of mortality among 15 - 24 years age group [10]. For instance, RTA injuries were the leading cause of youth death in 2012, with some 330 adolescents dying every day [11].

Occupational accidents, otherwise, stand alone as a specific source for "injury", probably due to the defined nature and circumscribed risks encountered with each occupation category. Generally, occupational accidents occur during working hours and/or on the way to and from the workplace. According to International Labor Organization (ILO), an occupational accident is a term covering any "occurrence arising out of, or in the course of, work which results in fatal or non-fatal injury" [12]. Such occurrences may involve unexpected incidents, including acts of violence in connection with work which results in workers incurring a personal injury, disease or death. Thereby, travel, transport or road traffic accidents in which workers are injured while at work or carrying on the business of the employer; in other words engaged in an economic activity, are incriminated [13].

As with non-occupational accidents, expectedly there is now a clearer discrimination between different types of occupational happenings terminologies. As per the Occupation Health and Safety Assessment Series (OHSAS) 18001 standards, an accident is regarded as a "particular type of incident in which an injury or illness actually occurs." An incident is referred to as "work-related event(s) in which an injury or ill health (regardless of severity) or fatality occurred, or could have occurred." A near-miss is an "incident where no injury or illness occurs." Therefore, an incident can be either an accident or a near-miss [14]. Finally, in the context of workers' compensation, accidents at work are regarded from the perspective of compensating the victim, and hence occupational accident definition contains the elements that allow linking the injury to the accident at work, if present, so the victim can claim compensation. The burden of occupational accidents and related injuries on the health status of the society's health and national economies is detrimental [11]. Worldwide, more than 337 million accidents happen on the job each year, resulting, together with occupational diseases, in more than 2.3 million deaths annually. Unsurprisingly, the type, mode, and severity of accidents and injuries while involved in an occupational activity vary by the nature of work, workplace environment, profession, working process, and sources of exposure and surrounding hazards, e.g., whether industrial, manufacturing, agricultural, constructional, commuting, healthcare- or social-work-related, etc. (Pretty much of such different work activities could be consolidated into two main groups: mechanical, such as sharp and blunt traumata, collision, wounds, crushing, and nonmechanical, such as poison, temperature, electricity and asphyxiation, and hence injuries would arise). In USA and Europe, for instance, every year more than one thousand workers die and another 250,000 are injured in industries.

Domestic-or home accidents are another type of injuries that are almost uniformly and consistently encountered, worldwide. They account for the majority of the injuries though often less severe [15]. The likelihood that most people of all ages, including old-age people, are at some degree of risk for domestic accidents is quite evident [16]. Domestic accidents involve accidents that take place at home or its immediate surrounding and more generally, not all accidents concerned with traffic, vehicle or sports. Otherwise, fall-flip-trip-slip-trauma; burns and scalds, electrocution, poisoning, drowning/near-drowning, animal bites; all are known mechanisms of accidents taking place within home environment. Children are at particular risk of those types of accidents, especially falls, fractures, scalds, wounds, bang trauma, poisoning (drugs, chemicals, household detergents, bleaches, swallowed foreign bodies), chocking, and near-drowning. Ensuring safety at house and indoors is effectively achievable through education to realize sources of risks, mechanism of injury, and appropriate safety measures. The burden of home accidents on the populations' safety and health is immense. Accidents at home kill more Europeans than RTAs, in spite of strict safety regulations controlling buildings and living areas [17]. The problem is graver in developing countries, particularly in rural areas, shanty towns or informal dwellings, where both safety laws enforcement is not as strict, and the public's safety culture is often low. In fact, most strategies to prevent accidents actually do not prevent them. However, these strategies may achieve tangible success in reducing the frequency and severity of injuries linked to accidents. Many of these strategies have been proposed, important of which are: 1) data collection: there should be a basic reporting system of all accidents, which help bringing out the risk factors of the accidents [18], 2) identification and elimination of the causative factors, e.g., improvement of roads, application of danger markers, and reduction of high voltage [19], 3) safety education, e.g., enhance public awareness of accident hazards of every day-life and first aid education [20], 4) promotion of safety measures, e.g., enforcing laws of medical fitness for driving, seat belts and helmets, (the latter two measures alone can reduce RTA-related mortality by $50 \%$ and $40 \%$, respectively) [21], 5) fire guard precautions, and 6) particularly control of drug addiction and alcoholism. With respect to addiction, it is reported that drug dependents are at higher risk for all types of accidents than others [22]. The provision of medical services, such as 
emergency units on the roads and at factories and industrial plants to facilitate management plays a remarkable role in minimizing post-accident disabilities [23]. The provision of maintaining and assuring safe workplace is every professional international and local occupational safety and health organization's concern. The ILO Constitution sets forth the principle that workers should be protected from sickness, disease and injury arising from their employment. Many of the occupational accidents are preventable through the implementation of sound prevention, reporting and inspection practices. In 2003 the ILO adopted a global strategy to improve occupational safety and health which included the introduction of a preventive safety and health culture, the promotion and development of relevant instruments, and technical assistance [24]. Both employers and workers have a responsibility to prevent the occurrence of work-related accidents; minimize their implications. The workers need to be aware of the safety rules on the worksites, build up on-the-job safety culture, e.g., not to under-estimate risk or committing negligent acts that jeopardize their well-being. Employers need to understand that the cost incurred complying with the safety and accident-prevention standards, e.g., those set by ILO, translates into less accidents and milder, if any, work injuries and hence the reward in the form of less compensation claims, enhanced workers' loyalty and productivity. Particularly raising the public's awareness of the dangers in the home so that accidents can be avoided is mandated, e.g., fire safety, electrical safety, heating and cooking safety, safety glass, safety with medicines and cleaners, and garden safety [25]. With this in mind, family members need to receive safety education in order to promote good housekeeping, not leaving items lying about on the floor, avoid trying out hands on “do-it-yourself” electrical or mechanical equipment; employ the services of professionals instead, not allowing wet flooring, ensure that children are kept out of reach of medicines, chemicals, sharps, and cooking areas. Absolutely, a book of rules is not a substitute for thinking ahead and acting right. Common sense and adherence to precaution rules are saviors in accident prevention. Other accident mechanisms as those occurrences when safety rules and regulations have been overlooked include unsafe practices by some groups vulnerable to particular types of injuries, such as the diabetics, the neurologically-and-the mentally disabled, and those with impaired agility, all are risk areas to be revisited in order to improve the safety standards at all community and public settings.

In Egypt, the public health system has its deep roots and involves an array of interlacing cultural, jurisdictional, and developmental factors. Since antiquity, Egypt's economic and societal interests have largely been based in the area around the River Nile. The Egyptian Nile has its unique course; it flows north until a point north of Cairo where it splits into two geographical branches that flow into the Mediterranean Sea and form the Nile Delta: the Damietta Branch (east) and Rosetta (west). The narrow valley on both sides of the Nile south of the Delta is known as "Upper Egypt". The valley is in continuity with a desert that is almost entirely uninhabited till present and that stretches out bilaterally until the borders of Egypt. Beginning in the late $18^{\text {th }}$ century and until the mid-20 ${ }^{\text {th }}$ century, Egypt was repeatedly invaded by the colonial Europe, namely Napoleonic France and Great Britain. This colonial stage was eliminated soon after the 1952 revolution. In the decades leading up to liberation, Upper Egypt in particular had been totally neglected from a socioeconomic standpoint; residents were impoverished and suffered extreme misery due to their lack of resources. However, an ambitious national development plan was established by the revolution and many successes were eventually achieved through it. These accomplishments entail a leading primary healthcare system to aid the traditionally under-served rural Egypt, and a nationalized health insurance and internal health system improvements program. However these successes were hampered by bouts of economic difficulties when tension between revolutionary Egypt and the Imperialistic pact started. By 1956, a tripartite British-French-Israeli invasion to reoccupy the Suez Canal was underway. While this occupation failed, another attempt in 1967 succeeded, as an Imperialism-supported Israeli invasion ended with Sinai under Israeli control. Although the invasion was counteracted by fierce Egyptian resistance, it was done so in a losing effort. Egyptian retaliation came six years later in swift fashion during the legendary 1973 war in which Egypt reclaimed its rights to the pat of Sinai that was still under occupation, and seemed poised to continue its march further east to liberate it all. However, some believe that the triumph of 1973 was negated by the halt of the Egyptian march and the later controversial Camp David accord after which Egypt regained its sovereignty upon all Sinai in 1982. Ever since the treaty, rural- and Upper Egypt began to suffer again. Unemployment and poverty have increased and the agricultural basis on which the Upper Egyptian economy is structured has decreased in prominence. Much work is needed to raise the living standard of the population and provide inhabitants with basic services and health protection. There is no doubt that the socially oppressed situation which residents of this part of the country live in has caused a decline in the efficiency of the health care system. As a result, the demand for increased health services in order to minimize the morbidity and 
mortality of diseases inflicting Upper Egypt has skyrocketed. Injury, accidents and disability are particular health problems which need an emphasis in any contemplated health development plan. In this context, and given the scarcity of research on addressing accidents' profile and associated burden in Upper Egypt, this work was an attempt to bridge the gap in knowledge of the epidemiology and risk factors associated with different types of accidents among male adults of Upper Egypt, specially examining the socioeconomic and risk factors concerning this challenge.

\section{Methods}

The study was undertaken in Quena University Hospital (QUH) in Upper Egypt. The hospital is a teaching health institution affiliated to the Quena Medical Center (QMC). The center receives referrals from the affiliated health institutions in Luxor and Red Sea governorates. Total 500 men 20 - 28 years of age seeking care at QUH were recruited between June 2012 and June 2013. Other than age and sex, admitted participants are those who have a medical record with QUH-QMC, or any of the affiliated hospitals in Luxor or Red Sea governorates. According to the study design, there could be a need to extract some information as measured in the patients' medical records. Subjects were informed that their consent to participate in the study would be considered a permission to access their medical records by these investigators for the purpose of this research. Refusal to give such permission was considered an apology to participate, and hence an exclusion from the study. Otherwise, necessary approvals from the institutional review board (IRB) of QMC have been granted. Selected participants were first informed of the study's aim, assuring them of the confidentiality of their personal information, and that only grouped data would be displayed for research purpose. Verbal acceptance to be selected among the study group was considered an informed consent to take part in this research. Nonetheless, participants were further informed that their participation is voluntary, and that they could opt to withdraw from the study at anytime without giving reasons and that such withdrawal cannot affect the healthcare benefits to which they are entitled. The study sample was randomly selected to represent the relative population size of the three participating governorates (Quena: 2,801,110, Luxor: 1,064,026, Red Sea: 321,079 populations) [26]. Two major approaches were adopted to collect study data: a validated predesigned questionnaire instrument and clinical interview, including medical record review. The questionnaire consists of five scales: a) Demographic and socioeconomic criteria, e.g. age, occupational history, including current and previous work/profession, role at work, residence, and marital status. The educational and income levels were measured as per Fahmy and El-Sherbini "socioeconomic scoring system of Egyptian population” [27]. A recent graduate may be one who has recently completed either a secondary-school-level degree, technical/associate degree, or a baccalaureate degree or above. (Usually, this group of participants is taking steps to joining their workforce and has not yet built up a work history). The second category consists of manual workers, whether or not they have a scientific or technical degree. The third group includes those who are currently jobless (either due to layoff or looking for another hob). Educationally, our study population is divided into two groups, those with a lower educational level (less than nine years of essential education and will be referred to in this research as $\leq \mathrm{K}-9$ ), or those with more than nine years of education (and will be referred to as $>\mathrm{K}-9$ ). b) Lifestyle and risk factors, e.g., physical activity, special habits, including drug dependence, c) health status, including chronic diseases, such as diabetes mellitus (DM), neurological problems, including manifest epilepsy, history of stroke, hospital admission. d) Health education (and screening attitude), e.g., engagement in health education, public safety activities. e) Accidents and bodily injuries scale, including history of accidents and unplanned incidents; mechanism, venue, surrounding environment, as well as bodily injury: severity, medical care received, including triaging and hospitalization, and outcome. (For the presence of history of injury, no specific injury severity scoring, e.g., ISS or diagnostic classification [28], could be uniformly used because different diagnostic methods were in used in the three governorates healthcare systems).Items on substance abuse were structured and phased in the context of "drug dependence” as per the WHO definition [29]. Included in the questionnaires, too, was a list of drugs and substances as per the ICD-10 classification of dependence producing drugs [30], including alcohol, opioids, cannabinoids (hashish or bango), sedatives or hypnotics, cocaine, other stimulants, hallucinogens, volatile solvents and multiple drugs, (tobacco was not included). (Examples of trade names of each drug group that are popular in the Egyptian drug addiction black market for Egyptian drug consumers were provided) [31]. Accordingly, in this research, the term "addict” or "drug addict” might be used in lieu of the term “drug dependent” because the word "addiction”, and often "narcotics addiction" is the exact word commonly used by most Egyptians to describe drug abuse habitual 
states we tend to identify in this research).For the outcome variable of interest, accident, as defined by Bird and Germain [3] and or incident as per the HSE definition. In our data collection policy, the term "accident” would be only used in reference to any of the two types of occurrences set-forth above, (near-miss was excluded from the data collection design). In the questionnaire, too, the scale on accidents and bodily injuries encompass three main subscales: the first is to tackle the accident place (domestic, occupational/workplace, RTA, railroad, and outdoor environment; each is further verified by the frequency of occurrence, so that one could have a history of more than one occurrence of the same category and more than one category during lifetime). Also, RTAs mechanism was further sub-categorized according to several criteria, e.g., whether the person was a passenger or a pedestrian, (RTAs while bicycling, skating, or on a motorcycle were also included). Particularly car crashes and collisions as a passenger would only be counted if the car damage exceeded LE650 (\$100 equivalent). The second subscale involves accident mechanism, e.g., fall, flip, trip, slip, sharp injury, blunt trauma, violence, including street fight, burn, scald, electrocution, near drowning, and “other” (to specify). (Poisoning was not included). (As before, each occurrence could have been encountered more than once; and more than one occurrence category during lifetime). Other definitions were as follows: occupational accident applies when the definition by OHSAS [14] has been met. Likewise, a positive response to domestic accident question means giving history of an accident that took place at home or its immediate surroundings. The scope of this work is mainly focuses on accidents rather than bodily injury following them. A rather "hybrid" classification of accidents consists of mechanism/place and personal behavior has been used. To the interest of our study population, the following categories of accidents, whether or not injury had been reported, are addressed: 1) RTA, 2) occupational accident, 3) domestic accident, 4) street fight/violence, 5) animal bite, 6) electrical accident/electrocution, 7) near-drowning, 8) falls, and 9) burn/scald.

A subject is said to be diabetic (type 1 or type 2) if there was a reported history of DM and a medical diagnosis, as concluded from his medical record based on the presence of criteria of a laboratory diagnosis of DM [32]. (Also, the presence of a history of receiving oral hypoglycemic and or insulin therapy, as well as symptoms of hyperglycemia or hyperglycemic crisis in the pertinent questionnaire response, especially when random plasma glucose (RPG) had been warranted thorough medical search to confirm the presence of DM) [33]. A pilot administration had first been conducted; test-retest reliability calculated to assess the temporal stability of the utilized questionnaire items. Reliability alpha ranging between 0.82 and 0.92 was recorded. Upon completing the questionnaire, each participant was invited to a clinical interview, medical record thoroughly examined, and then a clinical examination was carried out, including vital signs, visual acuity, and full systemic examination. The collected data were tabulated and analyzed using the Statistical Package for Social Science (SPSS) version 20. Frequency statistics, e.g., to describe interval- or ratio-scale data, such as age would be calculated using mean and standard deviation, considering normality distribution. Categorical variables were expressed in count and percentage; each category contrasted with the analysis reference category. Analytically, the socio-demographic characteristics of the study group would be identified and compared in the three governorates, e.g., using chi-square test of independence $\left[X^{2}\right.$ at degrees of freedom (df)], or Fisher's exact, where appropriate. Continuous variables, e.g., age, may be studies across the three governorates using the one-way ANOVA technique, as appropriate. Measuring the association between a risk variable of a categorical nature and the outcome (accident) among the study group, chi-square, or Fisher's exact tests, where appropriate would also be used; in which case, the odds ratio (OR) with its 95\% confidence interval (CI) could be used to express the strength of association between input variables and the outcome, and significance of the association, respectively. Further, our alpha error $(\alpha)$ to tolerate type-I error was 0.05 , and results with $p$-value less than alpha would be considered significant.

\section{Results}

Table 1 provides description of the socio-demographic traits of the studied population; the vast majority of whom were single (98.2\%) without a significant difference in the three governorates.

Most of Luxor and Red Sea residents (88.4\% and 78.0\% respectively) came from rural areas in their governorates, while only 8.5\% participants were from rural Quena $(p<0.001)$. With respect to occupation, 50.6\% of the study sample were recent graduates (looking for job), while the manual workers accounted 45\%, and lastly the unemployed (but not recently graduated) were only 4.4\% ( $p=0.0005)$. Overall, about two thirds (146 Quena, 156 Luxor, 30 Red Sea, total 66.4\%) of the study group belongs to middle socioeconomic class, $27.6 \%$ are low 
Table 1. Socio-demographic characteristics of the studied population.

\begin{tabular}{|c|c|c|c|c|c|c|c|c|c|}
\hline \multirow{2}{*}{$\begin{array}{l}\text { Socio-demographic } \\
\text { data }\end{array}$} & \multicolumn{2}{|c|}{$\begin{array}{c}\text { Quena } \\
(\mathbf{n}=200)\end{array}$} & \multicolumn{2}{|c|}{$\begin{array}{c}\text { Luxor } \\
(\mathrm{n}=250)\end{array}$} & \multicolumn{2}{|c|}{$\begin{array}{l}\text { Red sea } \\
(n=50)\end{array}$} & \multicolumn{2}{|c|}{$\begin{array}{c}\text { Total } \\
(\mathrm{n}=\mathbf{5 0 0})\end{array}$} & \multirow{2}{*}{$\begin{array}{c}\text { Test statistic, } \\
p \text {-value }\end{array}$} \\
\hline & No. & $\%$ & No. & $\%$ & No. & $\%$ & No. & $\%$ & \\
\hline \multicolumn{10}{|l|}{ Residence } \\
\hline $\begin{array}{l}\text {-Urban } \\
\text {-Rural }\end{array}$ & $\begin{array}{c}183 \\
17\end{array}$ & $\begin{array}{c}91.5 \\
8.5\end{array}$ & $\begin{array}{c}29 \\
221\end{array}$ & $\begin{array}{l}11.6 \\
88.4\end{array}$ & $\begin{array}{l}11 \\
39\end{array}$ & $\begin{array}{l}22.0 \\
78.0\end{array}$ & $\begin{array}{l}223 \\
277\end{array}$ & $\begin{array}{l}44.6 \\
55.4\end{array}$ & \multirow{2}{*}{$\begin{array}{c}X^{2}(\mathrm{df}=2)=298.6 \\
p<0.001) \\
F(\mathrm{df}=2,498)=3.86, \\
p=0.0229\end{array}$} \\
\hline $\begin{array}{l}\text { Age } \\
\text { (mean } \pm \text { SD) }\end{array}$ & \multicolumn{2}{|c|}{$21.88 \pm 1.96$} & \multicolumn{2}{|c|}{$22.46 \pm 2.44$} & \multicolumn{2}{|c|}{$22.12 \pm 2.06$} & \multicolumn{2}{|c|}{$22.2 \pm 2.23$} & \\
\hline \multicolumn{10}{|l|}{ Marital status } \\
\hline $\begin{array}{l}\text {-Single } \\
\text {-Married }\end{array}$ & $\begin{array}{c}199 \\
1\end{array}$ & $\begin{array}{c}99.5 \\
0.5\end{array}$ & $\begin{array}{c}244 \\
6\end{array}$ & $\begin{array}{c}97.6 \\
2.4\end{array}$ & $\begin{array}{c}48 \\
2\end{array}$ & $\begin{array}{c}96.0 \\
4.0\end{array}$ & $\begin{array}{c}491 \\
9\end{array}$ & $\begin{array}{c}98.2 \\
1.8\end{array}$ & $\begin{array}{c}X^{2}(\mathrm{df}=2)=3.79 \\
p=0.150\end{array}$ \\
\hline \multicolumn{10}{|l|}{ Occupation } \\
\hline $\begin{array}{l}\text {-Recent graduate } \\
\text {-Manual work } \\
\text {-Jobless }\end{array}$ & $\begin{array}{c}116 \\
70 \\
14\end{array}$ & $\begin{array}{c}58.0 \\
35.0 \\
7.0\end{array}$ & $\begin{array}{c}115 \\
131 \\
4\end{array}$ & $\begin{array}{c}46.0 \\
52.4 \\
1.6\end{array}$ & $\begin{array}{c}22 \\
24 \\
4\end{array}$ & $\begin{array}{c}44.0 \\
48.0 \\
8.0\end{array}$ & $\begin{array}{c}253 \\
225 \\
22\end{array}$ & $\begin{array}{c}50.6 \\
45.0 \\
4.4\end{array}$ & $\begin{array}{c}X^{2}(\mathrm{df}=4)=20.23 \\
p=0.0005\end{array}$ \\
\hline \multicolumn{10}{|l|}{ Social class } \\
\hline $\begin{array}{l}\text {-High } \\
\text {-Middle } \\
\text {-Low }\end{array}$ & $\begin{array}{c}16 \\
146 \\
38\end{array}$ & $\begin{array}{c}8.0 \\
73.0 \\
19.0\end{array}$ & $\begin{array}{c}11 \\
156 \\
83\end{array}$ & $\begin{array}{c}4.4 \\
62.4 \\
33.2\end{array}$ & $\begin{array}{c}3 \\
30 \\
17\end{array}$ & $\begin{array}{c}6.0 \\
60.0 \\
34.0\end{array}$ & $\begin{array}{c}30 \\
332 \\
138\end{array}$ & $\begin{array}{c}6.0 \\
66.4 \\
27.6\end{array}$ & $\begin{array}{c}X^{2}(\mathrm{df}=4)=13.56 \\
p=0.0088\end{array}$ \\
\hline \multicolumn{10}{|l|}{ Educational level } \\
\hline $\begin{array}{l}->9 \text { years } \\
-\leq 9 \text { years }\end{array}$ & $\begin{array}{c}144 \\
56\end{array}$ & $\begin{array}{l}72.0 \\
28.0\end{array}$ & $\begin{array}{c}181 \\
69\end{array}$ & $\begin{array}{l}72.4 \\
27.6\end{array}$ & $\begin{array}{l}24 \\
26\end{array}$ & $\begin{array}{l}48.0 \\
52.0\end{array}$ & $\begin{array}{l}349 \\
151\end{array}$ & $\begin{array}{l}69.8 \\
30.2\end{array}$ & $\begin{array}{c}X^{2}(\mathrm{df}=2)=12.53 \\
p=0.0019\end{array}$ \\
\hline
\end{tabular}

socioeconomic-class subjects, and remaining 6\% are highest class. Only the frequency of being of a low social class among the study group significantly differed in the three governorates [19.0\% Quena, 33.2\% Luxor, 34.0\% Red Sea; $\left.X^{2}(\mathrm{df}=4)=13.56, p=0.0088\right]$ (Table 1$)$. As regards education, participants were mostly $\geq \mathrm{K} 9$ educated $(349 / 500=69.8 \%)$, [Quena 144/200 (72.0\%), Luxor 181/250 (72.4\%), Red Sea 24/50 (48.0)]. More than one-half $(261 / 349=52.2 \%)$ of this educational group are university graduates and 88/349 (17.6\%) are secondary education-level graduates. The $\leq \mathrm{K}-9$ group accounted 151 (30.2\%) subjects; such that 54/151 (10.8\%) of them opted out of school while after K-9, 53/151 (10.6\%) had less than K-9 education and or can read and write, and 44/151 (8.8\%) are illiterate. The difference in educational standards in the three governorates was also studied. Only subjects with lower education standard $(\leq \mathrm{K}-9)$ significantly differed with that regard [Quena, and 26/50 (27.6\%), 69/250 (28\%) Luxor, 26/50 (52\%) Red Sea, respectively, $X^{2}(\mathrm{df}=2)=12.53, p=0.0019, p=$ 0.0019] (Table 1).

Table 2 displays the distribution of the study group individuals who had reported an engagement onto accidents by the mechanism of accident occurrence. Twenty-three accident events were reported (=4.6\% of the total study population). Road traffic accidents represented the highest percentage $(7 / 23=30.4 \%)$ (Table 1); followed by involvement into violent act and street fight which mount to 5/23 (21.7\%). Three (13.1\%) out of the twentythree reported accident events were in the form of bites. Occupational accidents, electrical injuries, and neardrowning, all were encountered $(2 / 23=8.7 \%$, each). The least frequent accident mechanisms to report were for falls and burns, where both accounted to only 1 (4.3\%) each.

As regards the risks for accidents in our study group, (Table 3), drug abuse, occupation (manual work), obesity, and epilepsy were significantly associated with accidents. For instance, drug abuse brings about six folds an increase of risk for accidents compared with not being drug abuser (OR = 6.35, 95\% CI: 1.64 - 24.58). Manual workers had more than three folds increased risk to be exposed to accidents than others (OR $=3.36,95 \%$ CI: 1.22 - 9.73). Obese persons were at higher risk for accidents as compared to non-obese ones (OR = 4.81, 95\% CI: 1.50 - 15.46). Diabetes had no significant influence on the occurrence of accidents in the study group (OR = 7.18, 95\% CI: 0.33, 76.8). Likewise, social class and accidents were not associated (OR = 1.81, 95\% CI: 0.35 8.21). Otherwise, epilepsy and accidents were highly significantly associated with each other (OR = 45.33, 95\% CI: OR = 45.33, 95\% CI: $3.94-518.01)$. 
Table 2. Distribution of accidents by accident mechanism $(n=23)$.

\begin{tabular}{ccc}
\hline Mechanism & Number & \% \\
\hline RTA & 7 & 30.7 \\
Street fight & 5 & 21.7 \\
Animal bite & 3 & 13.1 \\
Occupational & 2 & 8.7 \\
Electrical & 2 & 8.7 \\
Near-drowning & 2 & 8.7 \\
Fall & 1 & 4.3 \\
Burn & 1 & 4.3 \\
Total & 23 & 100.0 \\
\hline
\end{tabular}

Table 3. Risk factors for accidents.

\begin{tabular}{|c|c|c|c|c|c|c|}
\hline \multirow{3}{*}{$\begin{array}{l}\text { Risk factors } \\
\text { (reference categories) }\end{array}$} & \multicolumn{4}{|c|}{ Accidents } & \multirow{3}{*}{ OR } & \multirow{3}{*}{$95 \%$ CI } \\
\hline & \multicolumn{2}{|c|}{ No (477) } & \multicolumn{2}{|c|}{ Yes (23) } & & \\
\hline & No. & $\%$ & No. & $\%$ & & \\
\hline \multicolumn{7}{|l|}{ Drug abuse } \\
\hline $\begin{array}{l}\text {-No (486) } \\
\text {-Yes (14) }\end{array}$ & $\begin{array}{c}466 \\
11\end{array}$ & $\begin{array}{l}95.9 \\
78.6\end{array}$ & $\begin{array}{c}20 \\
3\end{array}$ & $\begin{array}{l}4.1 \\
1.4\end{array}$ & 6.35 & $1.65-24.58$ \\
\hline \multicolumn{7}{|l|}{ Obesity } \\
\hline $\begin{array}{l}\text {-No (469) } \\
\text {-Yes (31) }\end{array}$ & $\begin{array}{l}451 \\
26\end{array}$ & $\begin{array}{c}96.08 \\
83.8\end{array}$ & $\begin{array}{c}18 \\
5\end{array}$ & $\begin{array}{c}4.0 \\
16.2\end{array}$ & 4.82 & $1.50-15.46$ \\
\hline \multicolumn{7}{|l|}{ DM } \\
\hline $\begin{array}{l}\text {-No (496) } \\
\text {-Yes (4) }\end{array}$ & $\begin{array}{c}474 \\
3\end{array}$ & $\begin{array}{l}95.4 \\
75.0\end{array}$ & $\begin{array}{c}22 \\
1\end{array}$ & $\begin{array}{c}4.6 \\
25.0\end{array}$ & 7.18 & $0.33-76.8$ \\
\hline \multicolumn{7}{|l|}{ Epilepsy } \\
\hline $\begin{array}{l}\text {-No (497) } \\
\text {-Yes (3) }\end{array}$ & $\begin{array}{c}476 \\
1\end{array}$ & $\begin{array}{l}95.4 \\
33.3\end{array}$ & $\begin{array}{c}21 \\
2\end{array}$ & $\begin{array}{c}4.6 \\
66.7\end{array}$ & 45.33 & $3.90-518.01$ \\
\hline \multicolumn{7}{|l|}{ Occupation } \\
\hline $\begin{array}{l}\text {-Graduates (253) } \\
\text {-Manual work (225) } \\
\text {-Jobless (22) }\end{array}$ & $\begin{array}{c}247 \\
208 \\
22\end{array}$ & $\begin{array}{c}97.6 \\
81.6 \\
100.0\end{array}$ & $\begin{array}{c}6 \\
17 \\
0\end{array}$ & $\begin{array}{l}2.4 \\
7.6 \\
0.0\end{array}$ & 3.36 & $1.22-9.73$ \\
\hline \multicolumn{7}{|l|}{ Social class } \\
\hline $\begin{array}{l}\text {-Low (138) } \\
\text {-Middle (332) } \\
\text {-High (30) }\end{array}$ & $\begin{array}{c}130 \\
320 \\
27\end{array}$ & $\begin{array}{l}94.2 \\
96.4 \\
90.0\end{array}$ & $\begin{array}{c}8 \\
12 \\
3\end{array}$ & $\begin{array}{c}5.8 \\
3.6 \\
10.0\end{array}$ & $\begin{array}{l}0.61 \\
1.81\end{array}$ & $\begin{array}{l}0.23-1.67 \\
0.35-8.21\end{array}$ \\
\hline
\end{tabular}

\section{Discussion}

While data on epidemiology and burden of chronic diseases, particularly infectious diseases or nutrition, in developing countries are available and fairly reliable, such information is sorely lacking for injuries. Perhaps this explains why other problems may be perceived as more urgent, making trauma advocacy that much more difficult. According to the WHO, Egypt ranks in the top ten for the concentration of road deaths, accounting 41.6 per 100,000 citizens in 2009, and an estimated 12,000 annually [7]. At the present time, the incidence and the importance of the different killers of man are changing. Accidents are increasing and ranking near the top of the list. This change is not restricted to the developed world, but has also occurred in the developing countries [34]. The WHO (1999), (2014) [35], reported that accidents kill more adolescents and young adults than any other diseases because young people are more vulnerable due to their risky behaviors. The present work found that $4.6 \%$ 
of the studied young adults have been exposed to different types of accidents. Road traffic accidents constituted the highest one (30.4\%) which matched to most studies and surveys conducted worldwide. Burt and Fingerhut (1998) [36], for example, state that motor vehicle accidents in the USA constitute $28 \%$ of all types of accidents and rank the first. In Egypt, it is recorded that traffic accidents comprised more than one third (37.88\%) of other injuries and $82.7 \%$ of victims were males. The human risk factors for traffic accidents as well as the other types of accidents are nearly the same, including drug dependence, alcoholism and poor physical and mental status e.g., obesity, DM and epilepsy [37]. In the present work, obesity and epilepsy were found to have a significant role in occurrence of accidents. This finding was supported by several works; for instance, Shults et al. (2001) [38], also Monti et al. (2005) [22] stated that 38\% of traffic fatalities were alcohol-related; either the driver or an affected person (e.g., a pedestrian or a bicyclist). Svend (2001) [39], recorded that epileptics with short seizure free interval were at double risk to be involved in traffic accidents than normal people. Street fights are not only forbidden socio-moral behavior but also a medico-legal problem. Notably, adolescents and young adults especially males are the high risk group to be engaged in street fights. The present work revealed that street fights injuries constitute $21.7 \%$ of all accidents. Animal bite especially dog bites are public health problem in several countries as the main cause of rabies. Reliable data on animal bites are scarce in many countries making it difficult to assess its full impact on human health [40]. Further, $0.6 \%$ of the studied population had been exposed to animal bite.

A survey was achieved by Kamel et al. (2001) [41], and recorded that $0.2 \%$ of Alexandria population were victims to animal bite, while Hensley (1998) [42], in Virginia reported that only $0.05 \%$ of the city people were the victims. This difference was explained on the bases of the varied level of the urbanization of the studied people and their environment. Apparently, not all Egyptians are aware that the technologies that can save their lives are placed beyond their reach. But recently, some have started asking questions and consider safety features e.g., before an automotive purchase decision despite the significant additional expense to assure maximum safety standards. In 2012, the Ministry of Tourism established a Road Safety Training Center for the sector's commercial drivers. Some giant organizations which operate major facilities in Egypt have invested in road safety programs as part of their corporate social responsibility portfolios, but local automotive industry members have not. On November 2, 2011 students died in a collision between their bus and a truck in Sohag, Upper Egypt. On November 5, 2013, at least 18 more children died while trapped in a burning school bus following a pileup involving two trucks and several cars near the Nile Delta town of Beheira [43]. That same day Egypt's president instructed the Specialized Council for Community Development, affiliated with the Presidency, to formulate a comprehensive vision to prevent road accidents through the organization of working groups that will include road experts and researchers from the field in coordination with the competent state authorities. The council was advised to present a report. Hopefully comprehensive recommendations toward traffic safety plan Egypt so desperately needs would be provided. The plan expectedly will involve all concerned Cabinet departments in addition to agencies regulating the traffic and automotive industry. Such wide-ranging cooperative efforts are not Egypt's forte, owing to a convoluted bureaucracy, in which areas of responsibility overlap and follow-through on decision making is never a prompt or straightforward process. But an index of a government's competency is its ability to effectively allocate resources, and Egyptians now may be envisioned as growing wary of the lack of action to safeguard their health and well-being. Eventually, this work provides important findings. The epidemiology of accidents among males of the production age in Upper Egypt has been described, risks identified, and association between these risks and accidents has been determined. These findings can be beneficial, planning for prevention of accidents, especially the traffic-related and the occupational and the following injuries. Enforcing updated public and occupational safety laws in parallel with community mobilization and investment in establishing a safety culture, especially population at risk through an integrated plan considering partnerships, volunteer work, and incentives, all save Upper Egypt the multitude of health and economic losses incurred as a result of the current accidents trend.

\section{Funding}

Self-funded.

\section{Conflicts of Interest}

None. 


\section{References}

[1] Van den Broek, K. and De Beeck, R.O. (2001) Prevent, Belgium. Accidents and Incidents. European Agency for Safety at Work. http://oshwiki.eu/wiki/Accidents and incidents

[2] Heinrich, H.W. (1931) Industrial Accident Prevention: A Scientific Approach. McGraw-Hill, New York. Quoted in Hollnagel, E. (2009) Safer Complex Industrial Environments: A Human Factors Approach. CRC Press, Boca Raton.

[3] Bird, F. and Germain, G. (1966) A New Horizon in Accident Prevention and Cost Improvement, New York.

[4] Health and Safety Executive (HSE) (2004) Investigating Accidents and Incidents. A Workbook for Employers, Unions, Safety Representatives and Safety Professionals. UK.

[5] Statistical Report on Road Accidents in 1999-2000 (2003) European Conference of Ministers of Transport, Paris.

[6] Tursz, A. (1986) Epidemiological Studies of Accident Morbidity in Children and Young People. World Health Statistics Quarterly, 39, 257-267.

[7] World Health Organization (WHO) (2013) Global Status Report on Road Safety 2013. http://www.who.int/violence_injury_prevention/road_safety_status/2013/en/

[8] Waller, J.A. (1987) Injury: Conceptual Shifts and Preventive Implications. Annual Review of Public Health, 8, 21-49. http://dx.doi.org/10.1146/annurev.pu.08.050187.000321

[9] Nantulya, V.M. and Reich, M.R. (2002) The Neglected Epidemic; Road Traffic Injuries. BMJ, 11, 1142-1145.

[10] Centers for Diseases Control and Prevention (CDC) (1996) Involvement by Young Drivers in Fatal Motor Vehicle Crashes. MMWR, 45, 1049-1053.

[11] World Health Organization (WHO) (2014) Adolescents: Health Risks and Solutions Fact Sheet No. 345.

[12] International Labor Organization (ILO) (2002) P155-Protocol of 2002 to the Occupational Safety and Health Convention, 1981. Protocol of 2002 to the Occupational Safety and Health Convention (Entry into Force: 09 Feb 2005). 90th ILC Session, Geneva, 20 June 2002. http://www.ilo.org/dyn/normlex/en/f?p=NORMLEXPUB:12100:0::NO::P12100_ILO_CODE:P155

[13] European Commission, European Statistics on Accidents at Work (ESAW), Methodology (2001) http://ec.europa.eu/eurostat/ramon/statmanuals/files/ESAW 2001 EN.pdf

[14] Occupation Health and Safety Assessment Series (OHSAS) (2007) 18001 Occupational Health and Safety Management Systems Requirements Standard. http://www.ohsas-18001-occupational-health-and-safety.com

[15] Hmingthanzuala, Sanayaima, H.D. and Gambhir, T.S. (2011) Domestic Accidents in an Urban Health Training Centre. Indian Medical Gazette, 476-480. http://medind.nic.in/ice/t11/i12/icet11i12p476.pdf

[16] Halperin, S.F., Bass, J.L., Mehta, K.A. and Betts, K.D. (1983) Unintentional Injuries among Adolescents and Young Adults. Journal of Adolescent Health Care, 4, 275-279. http://dx.doi.org/10.1016/S0197-0070(83)80011-4

[17] Review of Evidence on Housing and Health: Background Document, Fourth Ministerial Conference on Environment and Health (2004) Budapest, Hungary, 23-25 June, WHO-EURO.

[18] National Committee for Injury Prevention and Control (1989) Injury Prevention: Meeting the Challenge. American Journal of Preventive Medicine, 5, 1-17.

[19] Pollack, D.M. and McClain, P.W. (1989) Trauma Registries: The Current Status and Future Prospects. JAMA, 262, 2280-2283. http://dx.doi.org/10.1001/jama.1989.03430160102039

[20] Hijar, M.C. and Kraus, J.F. (2000) Cross-National Comparison of Injury Mortality. International Journal of Epidemiology, 29, 517-521. http://dx.doi.org/10.1093/ije/29.4.715

[21] Frank, R., Bouman, D.A., Callagher, S. and Milner, R. (1992) Preliminary Study of Traumatic Injury Prevention Program. Psychology \& Health, 6, 129-140. http://dx.doi.org/10.1080/08870449208402029

[22] Monti, P.M., Tevyaw, T.O.L. and Borsari, B. (2004) Drinking among Adults: Steering, Brief Interventions, and Outcome. Alcohol Research and Health, 28, 236-244.

[23] Think First National Injury Prevention Foundation: History. (2005) http://www.thinkfirst.org/About/History.asp

[24] International Labor Organization (ILO). International Labor Standards on Occupational Safety and Health. http://www.ilo.org/global/standards/subjects-covered-by-international-labour-standards/occupational-safety-and-health lang--en/index.htm

[25] The Royal Society for the Prevention of Accidents. Preventing Accidents in the Home. http://www.rospa.com/home-safety/advice/general/preventing-accidents-in-the-home/

[26] Central Agency for Public Mobilization and Statistics (CAPMS) (2012) Arabic Republic of Egypt. http://www.sis.gov.eg/En/Templates/Articles/tmpArticles.aspx?ArtID=9\#.VTX-RCGqqko

[27] Fahmy, S.I. and El Sherbini, A.F. (1983) Determining Simple Parameters for Social Classification for Health Research. 
Bulletin of the High Institute of Public Health, 8, 95-107.

[28] Afifi, R. (2012) Impact of Trauma System Preparedness on the Outcomes of Severe Child Injuries, USA. Indian Journal of Surgery, 74, 456-461. http://dx.doi.org/10.1007/s12262-012-0449-0

[29] Joint United Nations Program on HIV and AIDS (UNAIDS/WHO) (2004) Epidemiological Fact Sheet. http://data.unaids.org/publications/fact-sheets01/egypt_en.pdf

[30] Siegel, M., Mowery, P.D. and Strauss, W.J. (2000) Trends in Adult Cigarette Smoking in California Compared with the Rest of the United States, 1978-1994. American Journal of Public Health, 90, 372-379. http://dx.doi.org/10.2105/AJPH.90.3.372

[31] Zaytoun, S., Afifi, R., Alsenbesy, M. and Ayoub, H. (2015) Patterns and Distribution of Drug Dependence and Associated Risk Factors among Male Youth in Upper Egypt. European Journal of Scientific Research, 131, 215-219.

[32] Afifi, R.M., Omar, S.R. and El Raggal, A.A. (2012) A Community Screening Plan for the Prevalence of Some Chronic Diseases in Specified Adult Populations in Saudi Arabia: 1-Prediabetes and Diabetes Mellitus. International Journal of Diabetes in Developing Countries. 19 April 2012. JDDC-D-12-00089.

[33] American Diabetes Association (ADA) (2011) Standards of Medical Care in Diabetes. Criteria for the Diagnosis of Diabetes. http://care.diabetesjournals.org/content/34/Supplement_1/S11.full.pdf+html

[34] Amira, G.S., Randa, M.A. and Nabil, A.R. (2001) A Pilot Study of the International Program for Prevention of Head and Spinal Cord Injuries in Alexandria. Bulletin of the High Institute of Public Health, 31, 233-254.

[35] World Health Report (1999) The Double Burden: Emerging Epidemics and Persistent Problems. WHO, Geneva.

[36] Burt, C.W. and Fingerhut, L.A. (1998) Injury Visits to Hospital Emergency Departments: United States, 1992-95. National Center for Health Statistics. Vital and Health Statistics, Series 13, No. 131, 1-76.

[37] King, D., Benbow, S.J. and Barrett, J.A. (1992) The Law and Medical Fitness to Drive: A Study of Doctors' Knowledge. Postgraduate Medical Journal, 68, 624-628. http://dx.doi.org/10.1136/pgmj.68.802.624

[38] Shults, R.A., Elder, R.W., Sleet, D.A., Nichols, J.L., Alao, M.O., Carande-Kulis, V.G., et al. (2001) Task Force on Community Preventive Services. Reviews of Evidence Regarding Interventions to Reduce Alcohol-Impaired Driving. American Journal of Preventive Medicine, 2, 66-88. http://dx.doi.org/10.1016/S0749-3797(01)00381-6

[39] Svend, L. (2001) Increased Driving Accident Frequency in Danish Patients with Epilepsy. Neurology, 57, $435-439$. http://dx.doi.org/10.1212/WNL.57.3.435

[40] Sacks, J.J., Kresnow, M. and Houston, B. (1996) Dog Bites: How Big a Problem? Injury Prevention, 2, 52-54. http://dx.doi.org/10.1136/ip.2.1.52

[41] Kamel, I.M., Salwa, E.T. and Iman, A.D. (2001) Pattern of Animal Bites in Alexandria. Bulletin of the High Institute of Public Health, 31, 715-731.

[42] Hensley, J.A. (1998) Potential Rabies Exposure in Virginia City. Public Health Reports, 113, 258-262.

[43] Mada Masr (2014) Eighteen Burned to Death, 18 Injured in School Bus Crash in Beheira. 5 November 2014. http://www.madamasr.com/news/18-burned-death-18-injured-school-bus-crash-beheira 